\title{
UNAS NOTAS SOBRE CONSTRUCCIONES COMPARATIVAS EN EL LENGUAJE POÉTICO DE LOS SIGLOS XVI Y XVII ${ }^{(*)}$
}

JOSÉ ANTONIO MAYORAL

Universidad Complutense, Madrid

El objeto de estas breves notas no es otro que señalar unos cuantos hechos $-\mathrm{y}$, si es posible, suscitar de paso alguna que otra cuestión- en relación con la forma particular que exhiben determinadas construcciones comparativas en el discurso poético de los siglos XVI y XVII.

Las citadas construcciones pertenecen a la modalidad de comparaciones que suelen conocerse bajo las denominaciones de estereotipadas o hiperbólicas, según los autores ${ }^{1}$, con las variedades formales que se reflejan en secuen-

(*) Las presentes páginas constituyen el texto de una Comunicación presentada al XXI Simposio de la Sociedad Española de Lingüística, celebrado en Granada los días 16-19 de diciembre de 1991.

1 Pueden verse, entre otras referencias, W. BEINHAUER, «La comparación», en El español coloquial. Madrid, Gredos, 1968, pp. 248-271; M. GARCíA-PAGE, «Frases elativas", en Actas del Congreso de la Sociedad Espafiola de Lingülstica. XX Aniversario. Madrid, Gredos, 1990, 1, pp. 485496; G. ORTEGA OJEDA, «Comparaciones estereotipadas y superlatividad», en Ib., II, pp. 729-737; I. TAMBA-MECZ, «Comparaisons hyperboliques», en Le sens figuré. París, PUF, 1981, pp. 144-147; G. VIETRI, «On some Comparative Frozen Sentences in Italian», en Linguisticae Investigationes, 14, 1990, pp. 149-174; A. ZULUAGA, «Locuciones elativasm, en Introducción al estudio de las expresiones fijas. Frankfurt, Peter D. Lang, 1980, pp. 146-149. 
cias, usuales en las manifestaciones discursivas de la vida diaria, como las que se aducen en las series de (1) y (2):

(l) a. blanco como la nieve

b. negro como la pez

c. dulce como la miel

d. amargo como la hiel

(2) a. más blanco que la nieve

b. más negro que la pez

c. más dulce que la miel

d. más amargo que la hiel

De las dos variedades señaladas, me limitaré en esta ocasión a la representada en la serie de ejemplos de (2), variedad que responde al esquema formal más generalizado de las usualmente llamadas comparaciones de superioridad, esquema que para nuestros fines puede quedar formulado bajo el esquema elemental que se propone en (3):

(3) $\mathrm{X}$ (CÓPULA) más ADJETTVO que $\mathrm{Y}^{2}$

y que representa, dicho sea de paso, la fórmula más ampliamente preferida por los poetas de los siglos áureos. Como primera muestra de tales preferencias, sirvan los ejemplos de (4) ${ }^{3}$ :

(4) a. ¡Oh más dura que mármol a mis quejas $y$ al encendido fuego en que me quemo más helada que nieve, Galatea!

(Garcilaso, 121)

b. Tú sola más cruel que fiera hircana...

(De la Torre, 252)

c. Mós dura sois, señora, que un diamante...

(Figueroa, 141) 260-278.

2 Vid. O. PRYTZ «Construcciones comparativas en español», en Revue Romane, 14, 1979, pp.

3 Los ejemplos de los autores citados están tomados de las ediciones siguientes: M. DE CERvantes, Poesías completas II. Madrid, Castalia, 1981; J. DE LA CRUZ, Poesfa. Madrid, Cátedra, 1983; F. DE Figueron, Poesía. Madrid, Cátedra, 1989; L. DE GÓngora, Obras poéticas. Nueva York, The Hispanic Society of America, 1921, 3. vols.; L. DE LEON, Obras completas castellanas. Madrid, BAC, 1967, vol. II; J. DE LOMAS CANTORAL, Obras. Valladolid, Diputación Provincial, 1980; F. DE QUEVEDO, Poesía original completa. Barcelona, Planeta, 1981; P. Soto DE RojAS, Paraíso cerrado para muchos. Jardines abiertos para pocos. Madrid, Cátedra, 1981; F. DE LA TORRE, Poesía completa. Madrid, Cátedra, 1984; G. DE LA VEGA, Poesías castellanas completas. Madrid, Castalia, 1972; L. DE VEGA, Obras poéticas I. Barcelona, Planeta, 1969. 
d. ¿Quien en tus pies veloces alas cría, con que corres ligera más que el viento? (Cervantes, 218)

e. ¡Oh boca más hermosa que la aurora...! (Lope de Vega, 409)

f. Deste más que la nieve blanco toro... (Góngora, I, 82)

g. Más hermosa que el sol que alumbra el día eres, por ser mi amante y ser mi esposa.

(Quevedo, 224)

Los ejemplos que anteceden servirán de punto de referencia para destacar, aunque sólo sea de modo muy escueto y elemental, algunos hechos que tal vez puedan resultar interesantes, no sólo desde una perspectiva poética, sino también lingüística, en relación con tan peculiares manifestaciones de esta modalidad de construcciones comparativas. En tal sentido, me referiré a:

1. algunos aspectos relacionados con las convenciones poético-linguísticas de los enunciados que sirven de marco a tales construcciones ${ }^{4}$;

2. algunos aspectos sobre la naturaleza de sus respectivos constituyentes, y

3. algunos aspectos referidos a la variedad de esquemas distribucionales de los mismos, en el espacio de una estructura sintáctico-versal.

1. En relación con el sistema de convenciones poético linguísticas: de naturaleza pragmática, semántica o formal, que parecen regir la constitución y funcionamiento discursivo de los enunciados en los que aparecen integradas estas construcciones, cabe hacer referencia, entre otros, a hechos como los que resumo a continuación.

a) Desde una perspectiva pragmática (literaria, para ser más precisos ${ }^{5}$ ), se puede observar que tanto los enunciados que sirven de marco a las construcciones comparativas, como las propias comparaciones en si, aparecen caracterizados por constantes marcas indicadoras de la presencia en los mismos del sujeto de la enunciación ${ }^{6}$, que, en el presente caso, deberá identificarse con las

4 Parto del supuesto de que todo texto poético es resultado de varios procesos de cifrado, en los que intervienen códigos de muy diversa naturaleza y complejidad, cuyas reglas actúan sobre los distintos niveles de los códigos de las lenguas naturales: fónico, gramatical, léxico. Vid. a este respecto V. M. DE AGUIAR E SILVA, «O sistema semiótico literário», en Teoría da literatura. Coimbra. Almedina, 1982, cap. 2, en especial pp. 99-105.

5 Me remito a este propósito a los distintos trabajos reunidos en J.A. MayoRal (ed.), Pragmática de la comunicación literaria. Madrid, Arco / Libros, 1987.

6 Utilizo los términos enunciado y enunciación en el sentido consolidado en la tradición lingüística francesa. Vid. C. KERBRAT-ORECCHIONI, La enunciación. De la subjetividad en el lenguaje. Buenos Aires, Hachette, 1986. 
diferentes manifestaciones textuales de lo que es usual llamar Yo poético o Yo textual ${ }^{7}$. Dicha presencia se hace patente en el enunciado a través de:

- elementos deícticos vinculados a las personas y a las coordenadas espacio-temporales generadas por el propio acto de enunciación poética: $Y O-T U$ $A Q U I-A H O R A$, en tanto que componentes de naturaleza textual: formas pronominales y desinencias verbales de primera y segunda persona, referencias espacio-temporales vinculadas a dichas personas, etc. ${ }^{8}$;

- manifestaciones explícitas de grados más o menos intensos de afectividad por parte del $Y O$ poético: presencia de interjecciones, formas exclamativas, etc.; y, sobre todo, y de modo muy notable,

- manifestaciones de diferentes actitudes axiológicas adoptadas por el YO poético 9 sobre el mundo de personas, objetos o acciones que configuran su propio referente textual. A todo lo cual habrá que añadir

- la adopción de una modalidad expresiva de carácter marcadamente hiperbólico $^{10}$, aspecto este que se resuelve, en no pocas ocasiones, en abigarrados ensartados de comparaciones en los límites de un solo enunciado. Como muestra muy moderada de tal forma de proceder, sirvan los versos de Lomas Cantoral que se reproducen en (5):

(5) ¡Oh Galatea, (1) al llanto mío más dura que peña, (2) y más que el viento ligera, (3) y más cruel que el mar airado! (70)

por no traer a colación series de comparaciones desmesuradamente extravagantes de algunos textos de Figueroa, Barahona o el mismísimo Quevedo, muestras de un verdadero frenesí comparativo, por más que cuenten con muy ilustres antecedentes en la poesía clásica.

b) Desde una perspectiva sintáctico-semántica, cabe indicar que en el conjunto de rasgos que caracterizan a esta modalidad de comparaciones, destaca el hecho, señalado en general por los estudiosos, de que, aunque configuradas sintácticamente bajo un esquema formal comparativo, tales construcciones

7 Un buen resumen de las diferentes posiciones criticas en torno a las figuras del YO en el texto literario puede verse en V.M. DE AGUIAR E SILVA, «Autor empirico, autor textual, narrador*, en op. cit., pp. 212-223.

8 C. Kerbrat-Orecchion, \&Los deícticos», en op. cit., pp. 45-91.

9 lbld., «Los subjetivemas "afectivo y evaluativo"; axiologizacion y modalización», pp.91-131.

10 No en vano algunos autores, asf I. TAMBA-MECZ, designan este tipo de construcciones con la denominación de «Comparaciones hiperbolicas». En relación con el concepto de Hipérbole puede tenerse en cuenta F. RAVAZZOLI, \&I meccanismi linguistici dell' iperbole», en Retorica e critica letteraria. Bolonia, Il Mulino, 1978, pp. 69-86. 
constituyen en realidad una forma de expresión de valores claramente superlativos $^{11}$. Hecho que puede comprobarse sin dificultad mediante los correlatos que siempre es dable establecer entre estas construcciones y las formalmente superlativas, con las que pueden ser parafraseadas. Ello sin contar los frecuentes ejemplos, en el discurso poético de los siglos XVI y XVII, de construcciones comparativas explícitamente superlativizadas - valga la expresión-mediante la anteposición a las mismas del cuantificador muy, como muestran las secuencias de (6):

(6) a. Más dura sois, señora, que un diamante y muy más brava sois que una leona... (Figueroa, 141)

b. Virgen, muy más que el sol resplandeciente... (L. de León, 832).

2. Voy a referirme a continuacion a algunos aspectos que tienen que ver con la naturaleza de los distintos constituyentes sintagmáticos implicados en la configuración específica de esta modalidad de construcciones comparativas, en especial, el núcleo y el término subordinado de la comparación, por seguir la terminología adoptada por O. Prytz ${ }^{12}$.

Como ya se habrá podido observar, el núcleo adjetival de las comparaciones insertas en los ejemplos propuestos hasta ahora está constituido regularmente por elementos de la categoría particular de adjetivos que algunos autores denominan como evaluativos o, más concretamente, evaluativos axiológicos $^{13}$, clase de adjetivos cuyo empleo implica, según observan tales autores, la actuación de una doble norma: una norma referida a la clase de personas, objetos, acciones o acontecimientos a los que se atribuye una cualidad o propiedad, y otra norma referida al sujeto de la enunciación, y relativa a sus sistemas de evaluación. Se trata, en suma, de una clase de adjetivos que aplica a las realidades denotadas por los sustantivos que modifican, un juicio de valor positivo o negativo, juicio de valor que habrá que interpretar, claro es, de acuerdo con el sistema de valores vigente en el interior de un marco cultural dado. No hará falta señalar en este punto que es dentro del ámbito de operatividad de tal

11 Cfr. las referencias de GARCIA-PAGE y ORTEGa OJEDA aducidas en nota 1 y J.M. GonZÁLEZ CALvo, «Sobre la expresión de lo superlativo en español (II)», en Anuario de Estudios Filologicos, 8, 1985, pp. 114-146, especialmente las pp. 137-146.

12 Véase nota 2.

13 C. KERBRAT-ORECCHIONI, en la referencia de la nota 9. 
sistema de valores donde se regulará, en gran medida, el funcionamiento discursivo del sistema linguiístico de la superlatividad en buena parte de las manifestaciones de la interacción comunicativa de la vida diaria.

Ahora bien, sin dejar de reconocer la importancia de hechos como los que se acaban de mencionar, pienso que nuestro intento de llegar a comprender, de modo más ajustado, la forma y el funcionamiento discursivo de las construcciones comparativas a las que me vengo refiriendo, debe pasar por la indagación de la operatividad de los sistemas axiológicos particulares desarrollados por las propias tradiciones poéticas, dentro del sistema general de valores vigente en el marco cultural de referencia, y que deben ser considerados como parte integrante del sistema de convenciones que permite caracterizarlas y comprenderlas. Puede pensarse a este propósito en los sistemas de valores inherentes a tradiciones poéticas como la trovadoresca, petrarquista, clasicista, romántica, etc., en lo que se refiere a los paradigmas de cualidades que describen $-\mathrm{y}$ al mismo tiempo valoran - el mundo de personas, objetos o acciones que conforman los referentes poéticos dominantes en obras pertenecientes a dichas tradiciones ${ }^{14}$.

Así pues, sólo en el interior del sistema de valores inherentes a las convenciones poeticas que caracterizan algunas de las corrientes en que se canaliza la actividad poética de los Siglos de Oro $^{15}$, podrán ser comprendidos los paradigmas de cualidades expresadas por los adjetivos que, tanto en sus sentidos propios como figurados, sobre todo éstos últimos, constituyen de modo recurrente los núcleos de las construcciones comparativas que vienen siendo objeto de atención en estas páginas.

Por lo que respecta al término subordinado de la comparación, me contentaré con hacer referencia a los dos aspectos siguientes.

Resulta obligado referirse, en primer término, a un hecho que tiene que ver con la naturaleza semántico-pragmática de la clase de sustantivos susceptible de constituir el núcleo del sintagma nominal que funciona como término subordinado de la comparación. Como bien se sabe, uno de los rasgos más sobresalientes de esta modalidad de comparaciones radica en el hecho de que el referente denotado por tal clase de sustantivos se ha consolidado culturalmente como arquetipo, dechado o modelo ejemplar ${ }^{16}$ de la cualidad expresada por el adjetivo que figura como núcleo de la respectiva comparación.

14 No tengo conocimiento de que se haya planteado, en los estudios de Poética, un análisis de problemas de esta índole, que no debería faltar en el estudio de los sistemas de convenciones linguístico-poéticas que configuran las tradiciones poéticas.

15 Puede verse a este respecto J.M. BLECUA, «Corrientes poéticas en el siglo XVI», en Sobre poesía de la Edad de Oro. Madrid, Gredos, 1970, pp. 11-24.

16 I. TAMBA-MECZ, op. cit., p. 146. 
Las preferencias mostradas por los poetas del periodo áureo, en lo que a selección de arquetipos se refiere, no se alejan en principio de los inventarios de elementos físico-naturales, de animales reales o fabulosos, de personajes históricos o mitológicos que, desde tiempos remotos, se han venido erigiendo en dechados de cualidades físicas o morales, polarizadas en virtudes y vicios, tanto en el ámbito general de nuestra tradición cultural, como en el ámbito particular de las tradiciones literarias y poéticas que en ella se han venido desarrollando ${ }^{17}$. Ahora bien, no son raros los casos en los que se trascienden los paradigmas de arquetipos que nos pueden resultar más familiares y asequibles, dados los continuos alardes «culturalistas» mostrados por los poetas en esta particular forma de conocimiento enciclopédico, siempre de lo más sorprendente e imprevisible para un lector que no esté ligeramente familiarizado con las variadas informaciones contenidas en la difundida Officina de Ravisius Textor $^{18}$.

En segundo término, no puede pasarse por alto un hecho que llama poderosamente la atención, en relación con la configuración lingǘrstica del término subordinado de la comparación en su conjunto. Me refiero concretamente a la manifiesta proclividad de los poetas por expandir o alargar el sintagma nominal, base de dicho término, con toda suerte de complementaciones: sintagmas adjetivales, sintagmas preposicionales, oraciones de relativo, fórmulas todas que vienen a confirmar, en última instancia, el ya aludido carácter hiperbólico de esta particular modalidad de construcciones comparativas. Así, frente a formulaciones escuetas como la del ejemplo de (7):

(7) Lícida mía, más que el sol hermosa.

(De la Torre, 203)

en donde el término subordinado de la comparación está reducido a la partícula comparativa que + SN: que el sol, proliferan por todas partes comparaciones en las que dicho término adquiere grados de incrementación como los que encontramos en este ejemplo de Lope de Vega:

(8) ¡Oh boca más hermosa que la aurora

$[+$ que [+ con el blanco aljófar del rocio $]$

las flores baña [+ ilustra, + aumenta, + y dora]]!

(Lope de Vega, 409)

17 Resulta muy instructiva a este respecto la consulta de M.P. MANERo SOROLLA, Imágenes petrarquistas en la lírica espaniola del Renacimiento. Barcelona, PPU, 1986.

18 Officinae Joannis Ravisii Textoris Epitome. Lugduni, Apud Sebastianum de Amoratis, 1559. 
3. Voy a pasar a referirme, por último, a algunos hechos que, por lo que he podido ver, no suelen ser objeto de especial atención en el tratamiento de este tipo de construcciones. Se trata de las distintas variedades distribucionales que los constituyentes antedichos: núcleo y término subordinado de la comparación, pueden presentar en el espacio de la estructura sintáctico-versal.

En general, parece darse por supuesto que la ordenación en la distribución de los constituyentes de la construcción comparativa es la que se corresponde con el orden reflejado en el esquema formulado anteriormente en (3). Tal ordenación representa, bien es cierto, la que parece ser la fórmula más consolidada en el uso linguístico, desde los origenes del idioma hasta el momento presente, en todas sus variedades y registros, formula que, como se habrá padido observar, también está representada en buena parte de los ejemplos aducidos.

Ahora bien, junto a la vigencia de este esquema distribucional, que cabe considerar normal en el uso linguístico generalizado, la tradición lingüística particular que, en el interior del código general de la lengua, constituye el lenguaje poético, ha desarrollado otras variedades distribucionales especificas que no pueden quedar ajenas a nuestro actual interés.

Tal es el caso de los esquemas que trataré de sintetizar a continuación, esquemas documentados en mayor o menor medida en la práctica totalidad de los autores consultados.

a) Prescindiendo de la variedad que se ha considerado normal, destaco, en primer lugar, la representada por un esquema distribucional como el de los ejemplos de (9):

(9) a. Flérida, para mí dulce y sabrosa más que la fruta del cercado ajeno.

(Garcilaso, 205)

b. ¡Oh noche amable más que la alborada! (San Juan de la Cruz, 260)

variedad documentada muy por extenso en todos los textos poéticos de los siglos XVI y XVII, y cuya presencia en la tradición poética se remonta a fechas bastante tempranas.

Las variedades siguientes, de uso más restringido, representan esquemas distribucionales mucho más especificos del discurso poético de dicho período.

b) Tal es el caso del esquema reflejado en los ejemplos de (10):

(10) a. Virgen que el sol más pura...

(L. de León, 790) 

b. ... y sale al mundo aquella prudentisima Ester, que el sol más bella. (Cervantes, 318)

ejemplos en los que no resultará difícil observar el fenómeno retórico de Inversión ${ }^{19}$ en el orden de los constituyentes, paralelo al que cabe encontrar entre los complementos preposicionales de sustantivos y adjetivos, de tan abrumadora presencia en los textos poéticos de este periodo, y de los que pueden servir de muestra las secuencias de (11):
a. Yo estoy aqui tendido, mostrándoos de mi muerte las señales. (Garcilaso, 78)
b. ... y el prado ameno vido de flores y de sombra lleno. (Garcilaso, 196)

c) Como tercera variedad de esquema distribucional de constituyentes, cabe citar la representada por los ejemplos de (12):
a. ... con sospiros calientes mas [que la llamal] ardientes.
(Garcilaso, 132)
b. Deste mas [que la nieve] blanco toro... (Góngora, I, 82)

en los que nos encontramos ante un fenómeno de incrustación de todo el término subordinado de la comparación en el espacio interpuesto entre el cuantificador más y el núcleo adjetival correspondiente, fenómeno que no resultará difícil asociar con las escisiones y dislocaciones de constituyentes producidas por el mecanismo retórico del Hipérbaton ${ }^{20}$, tanto en el interior de estructuras

19 Vease la nota siguiente.

20 Para una exposición de la concepción del Hipérbaton en la doctrina retórica tradicional, puede verse H. LAUSBERG, Manual de retórica literaria. Madrid, Gredos, 1966-1967, \$§ 716-718. En relación con el uso de esta figura en el discurso poético de los siglos XVI y XVII, basten estas breves referencias: D. ALONSO, La lengua poética de Góngora, en Obras completas. Madrid, Gredos, 1987, V, pp. 188-226; Vida y obra de Medrano. Madrid, CSIC, 1948, pp. 180-202; R. LAPESA, «El cultismo en la poesía de Fray Luis de León», en Poetas y prosistas de ayer y de hoy. Madrid, Gredos, 1977, pp. 128-145; J.M. POZuELo YVANCOS, «El hipérbaton», en El lenguaje poético de la lirica amorosa de Quevedo. Murcia, Universidad de Murcia, 1979, pp. 319-335; M. GARClAPAGE, «Tipología del hipérbaton en Cervantes*, en Etudes Hispaniques, 22, 1994, pp. 269-279. 
nominales como verbales, y de las que pueden servir de ejemplo fragmentos textuales como los que se aducen en (13), en el ámbito nominal solamente:

(13) a. Esta [de llanto amargo] eterna fuente...

(Figueroa, 150)

b. ... antes podrás matarme

con la cruel [que empuñas] media lanza.

(Soto de Rojas, 195)

d) Por último, y como variante del caso anterior, puede considerarse el esquema reflejado en (14):

(14) a.

Más intractable,
$\downarrow$
$\downarrow$
que el mar hinchado,

(De la Torre, 223)

b.

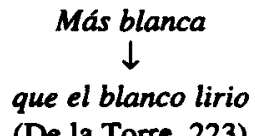

más endurecida

$\downarrow$

que la sierra helada.

(De la Torre, 223)

variedad que constituye un ejemplo del artificio conocido bajo la denominación de Versus rapportati, Correlación en términología de D. Alonso ${ }^{21}$, artificio basado en una correspondencia sintáctica de orden vertical entre determinados constituyentes del enunciado.

Para concluir estas breves notas sobre las comparaciones hiperbólicas, en la forma en la que aparecen insertas en el discurso poético de los siglos XVI y XVII, me permito sugerir que una vía de indagación que nos permita alcanzar un conocimiento más satisfactorio de aspectos como los que he venido apuntando en estas páginas, deberá transitar por una doble vertiente.

a) Por un lado, resulta necesario examinar, con minuciosa atención, la tradición de convenciones y artificios lingüístico-poéticos que configuran el propio lenguaje poético en el interior del devenir del sistema general de la lengua. En el caso concreto del sistema de convenciones y artificios del lenguaje poetico de los siglos XVI y XVII, presenta especial relevancia un hecho de tan

21 Artificio poético-retórico al que $D$. Alonso dedicó numerosos e importantes estudios. Pueden verse, entre las muchas referencias que cabría aducir, «Versos plurimembres y poemas correlativos», en Revista de la Biblioteca, Archivo y Museo del Ayuntamiento de Madrid, 13, 1944, pp. 89-191, así como los trabajos reunidos en el volumen en colaboración con C. BousoNo, Seis calas en la expresión literaria espaftola. Madrid, Gredos, 1970. 
amplia repercusión textual como es la norma poético-retórica de la «imitación de modelos» ${ }^{22}$. Un estudio más comprensivo de aspectos como los señalados a lo largo de estas notas, deberá pasar, por tanto, por un examen de sus correlatos, tanto de orden material como formal, en la poesia (greco-)latina, en primer término, $y$, en segundo término, en la poesia italiana representada tanto por Petrarca como por los poetas italianos del Renacimiento ${ }^{23}$. En este punto resultará siempre sorprendente la fidelidad guardada a los modelos.

b) Ahora bien, la indagación de aspectos de carácter histórico no debe hacer olvidar la búsqueda de razones de orden estructural, es decir, el conjunto de leyes reguladoras de la constitución, en cada etapa de su devenir, del propio discurso en verso: la interrelación entre medida silábica, diseño rítmico, esquema de rimas, conjunto estrófico, etc. El análisis de estos aspectos ayudará a comprender, entre otros hechos, la adopción en el espacio concreto de cada texto de una u otra de las variedades distribucionales que se han enumerado anteriormente, adopción que puede considerarse inducida en cada manifestación concreta por leyes internas del discurso en verso ${ }^{24}$.

O dicho más brevemente. Si razones históricas pueden dar cuenta de las preferencias, temáticas y formales, de esta modalidad de construcciones, serán razones estructurales las que podran explicar la adopción en cada «espacio textual» de una de las diferentes posibilidades de variación distribucional que ha consolidado la propia tradición poética.

22 Puede consultarse a este respecto A. Garcta Gallano, Teoría de la imitación poérica en el Renacimiento. Kassel, Reichenberger, 1992.

23 A tal propósito es modélico el estudio de M.R. LIDA, «El esquema 'Flérida, para mí dulce y sabrosa / más que la fruta del cercado ajeno'», en $R F H, 1,1939$, pp. 52-63.

24 De acuerdo con uno de los más fecundos postulados de la doctrina del método formal. Vid. T. Todorov (ed.), Théorie de la littérature. París, Seuil, 1965, passim y J. TYNJIANov, Le vers luimême. Parfs, UGE, 1977. 